This is an author produced version of a paper published in:

Pohjannoro, U. (2021). Mind the body: Materiality and physicality in a composer's thinking process. Psychology of Music. Copyright (C) 2021 Ulla Pohjannoro. https://

doi.org/10.1177/03057356211034916

\title{
Mind the body: Materiality and physicality in a composer's thinking process
}

First Published 20 Nov 2021

Ulla Pohjannoro

ORCID iD https://orcid.org/ 0000-0002-7473-5865

\section{Abstract}

This exploratory case study investigated the grounds of the material and physical aspects of compositional thinking, viewing musical composing as organizing the world of sounds. The data tracks one compositional process, including the full body of the manuscripts and verbal data accounting those manuscripts. The results present a composer, who wishes to create music that has performative power, that is, expressivities that have the capacity to move the mind of the listener. The composer is inspired by the materiality of sound and musical instruments, but on the other hand constrained and challenged by the corporal affordances of performers and their instruments as well as by the (im)practicalities and intelligibility of notational practices. Five different aspects of materiality were identified: (1) visual images and representations, (2) the score as the material object of composition, (3) the material and physical affordances of musical instruments, performers that play them, and sounds that are produced by them, (4) physical reactions entailing embodied intuitive knowledge of the composer, and (5) metaphoric processes, where the composer, when shaping timbres and musical structures, "pushes," even "forces" sounds to "move" and sound in a way that is meaningful and transpires to the listener as music that moves the mind.

Keywords

gesture, performance, metaphors, musical composition, materiality, physicality, expression

Within musical practice, composing is considered the mental, intellectual and creative form of musical practice, par excellence. In contrast, the work of a performer seems to be substantially practical, reproductive and corporeal. This study aims to challenge this common notion of the exclusive mentality of compositional work and claims that a composition, a score, encompasses material ingredients that entail, and are prerequisite for, facets of physical action. Through exploring how material and physical matters manifest in the compositional process and analyzing their origins and implications for composition, I will demonstrate that working in the solitary studio of a Western art music score-based composer - notwithstanding the intellectual nature of their compositional activities - is in almost every instant grounded in materialities of different kinds and attained by non-propositional practical understanding. This practical understanding originates in the material and physical aspects of sound and the action of producing that sound. It manifests itself in the way the producers of sounds and timbres, such as the performer with their movements and instruments, persist in the working mind of a composer. Moreover, creative thinking entails bodily activity by the composer, which transpires in the form of an intuitive mode of reasoning. 
While acknowledging that composing entails observable motor actions, such as inscribing the score, experimenting with musical instruments, working with colleagues, musicians, publishing and recording companies, agents, producers and other actors of the music world, I will focus on the material aspects of the "mind's work," concealed in the seemingly abstract and motionless compositional thinking process. I will first theorize materiality and physicality of composing in musicological and psychological composition research. Then, I will substantiate my argument with the empirical data covering one complete compositional process by a professional composer. These data have already lent themselves to various theoretical frames in studies addressing different research aims (Pohjannoro, 2008, 2014, 2016, 2020; Pohjannoro \& Rousi, 2018).

\section{Materiality and physicality in composition research}

The term material in composition research usually refers to the quite abstract musical material that consists of musical notes, sounds, and timbres (e.g., Reybrouck, 2006; Reynolds, 2004; Roels, 2016). Physical matters may appear in the form of occasional research outcomes that touch on visual outlines, writing a score, instrumentation, or handling a musical instrument (e.g., McAdams, 2004; Roels, 2016; Zembylas \& Niederauer, 2018). The studies by Donin and Féron (2012) identify the roles of inner hearing, musical instruments and idiomaticity, and, indeed, the overall enactive and embedded existence of those. The scholars embrace the situatedness of compositional cognition, viewing that every compositional act rests not only on compositional decisions but on the compositional tools (writing equipment, music paper, computers, software) and physical as well as societal (colleagues, musicians, music and recording engineers, agents, etc.) environments within which the process takes place.

Zembylas and Niederauer (2018) outline the topography of compositional practices shared with peers and non-peers in corpore as well as assisted by material and immaterial objects. They discuss the personal compositional tools of a composer (computer, pen) and recognize the non-discursive form of compositional knowledge that is experiential, procedural, and embodied in nature. They define artistic practical knowledge (as opposed to propositional knowledge) as comprising body knowledge (e.g., knowledge through body), situated knowledge ("anchored in cultural traditions, past experiences, and habituated modes of thinking," p. 81), and knowledge of work processes (experiential knowledge; pp. 98-101), which all more or less render the outcomes of the "intuitive working mode" (pp. 37, 91, 97; Hodgkinson et al., 2008) of compositional thinking.

The cognitive model of composing presented in an interview study by Katz (2012; Katz \& Gardner, 2012) proposes different sources of materiality in composition, according to the type of the cognitive process utilized: (1) the materiality of purely musical sources, that is, hands-on improvising and kinaesthetic perception with musical instruments among intuitively processed within-processes and (2) the materiality of extra-musical sources, that is, the conceptual framework and their reflection and metaphoric transgression into musical entities among reflectively processed beyond-processes.

Schiavio et al. (2020) view the compositional process as "largely exploratory, grounded in bodily experience, and emerging from the recursive dialogue of agents and their environment" (p. 1). Aligned with 4E cognition paradigm (holding that cognition is embodied, embedded, extended, and enactive; Ryan \& Schiavio, 2019), they show through an open-ended questionnaire data of 15 composers how they engage with music and connect to 
music more than generate it, how they "develop intimate forms of reciprocal interplay with musical instruments" (Schiavio et al., 2020, p. 10) and how "the interactions established between composers and their music are therefore not only figurative, but rather based on agency and bodily connections" (p. 11). Similarly, my recent study showed that even the most abstract configurations of compositional cognition are fundamentally rooted in the physicality of sound that has material origins because having been produced by the material instruments (or by other objects/functionalities) through the physicality of the performers (Pohjannoro, 2020; see also Hovland, 2017, 2019; Reybrouck, 2006). In this study, ecologically valid evidence will be presented to support the claim on compositional materiality through a case study of an academically trained sheet music composer.

\section{The informant, method, data, and the complete composition of the study}

The informant in this study is a professional composer within Western modernist tradition. In the time of the data production (2004-2005) he was in his 40s and had been active on national and international art music scene for about 20 years and has later gained some international recognition. ${ }^{1}$ The data of the study were produced for the purpose of tracking the complete thinking process and compositional decisions of the composer-informant, ${ }^{2}$ by visiting his studio every fortnight during four months' time. The extensive data, in the possession of the researcher, encompass copies of all the respective manuscripts ( 22 items) and interviews (406 minutes, 29,000 words transcribed verbatim) facilitated by those manuscripts.

Instrumental case study design (Stake, 2005) applied in this study has been able to produce important knowledge about creative processes by producing a deep insight into a phenomenon that is not only complicated and lengthy but also extremely private. The disturbance of the process (Collins, 2005), masking of non-verbal matters (Hoffman et al., 1995), memory loss (Ericsson \& Simon, 1984/1993), and lack of integrity ${ }^{3}$ were in the current study controlled by conducting the interviews with the facilitative help by the newly made sketches. Reactive behavior (Gass \& Mackey, 2000; Jack \& Roepstorff, 2002), for example, the composer-informant explaining what he usually does or what one was supposed to do, was minimized through pinpointing the object of speech into a specific area in the manuscripts. During the interview sessions, my core question was "Can you tell me what you have done here? What is new?" after which I usually posed clarifying questions in order to understand the reasoning and aspirations of the composer-informant.

Due to the epistemic rationale and methodological approach, the data turned out to be exceptionally rich, lending itself even to intuitive processing, without asking the composerinformant directly about emotional, material, or physical matters (Pohjannoro, 2012, 2014, 2016 ; cp., i.e. Schiavio et al., 2020). The anonymity of the composer-informant freed him to expose his process in a remarkably frank way, even including moments of perplexity and complete exhaustion - not covered, to my knowledge, to such an extent in any other composition study.

The data analysis was grounded in the analytic frames of mapping the timeline of the process (Pohjannoro, 2008), identifying different modes of intuitive and analytic compositional actions (Pohjannoro, 2014, 2016) and knowledge (Pohjannoro \& Rousi, 2018), and exploring the levels of explication between those (Pohjannoro, 2020). For the purpose of this study, qualitative data-driven thematic analysis was executed to extract verbalisations that expressed material and physical aspects or conceptual metaphors. The drawings in the manuscripts were interpreted and cross-validated (Ericsson, 2003) with the help of the matching interview data 
accounting for those manuscripts. Last, member check validation was performed (Lincoln \& Guba, 1985): the composer-informant held with the manuscript examples, translations, and interpretations in the article and approved it to be published anonymously.

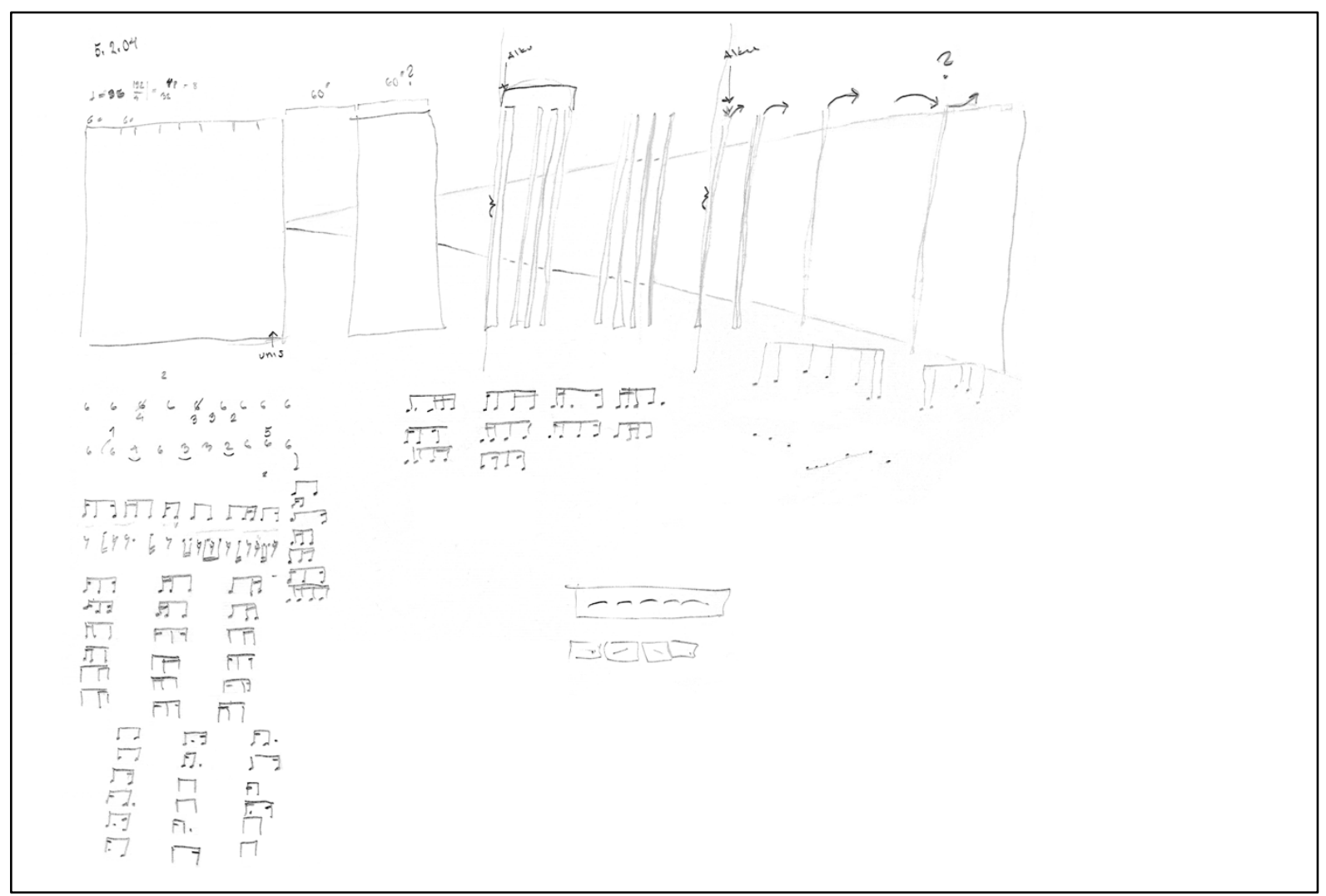

Figure 1. The first sketch of the piece, May 5th, 2004, collected dec 28th, discussed also in the interview Jan 5th.

Note. The formal structure of the whole piece depicts "Linear Music" with square blocks; the width of the square indicates time. "Space Music" is depicted with wedges behind the squares, symbolising the idea of "growth."

The complete composition of the study is a 15 minutes' percussion quartet. The core idea of the composer-informant was to investigate the experience of time in music. For this benefit, he fabricated two basic materials: Linear Music (L) represents chronological time and is written with a traditional time signature, whereas Space Music (S) reflects cyclical time and utilizes proportional notation. Linear Music is based on basic rhythm cells (dactyl, trochees, and spondees; see Figure 1 and rehearsal nr. 1.11 in Figure 2) whereas Space Music is crafted out of tremolos, repetitive and melodic elements (see Figure 2, rehearsal nr. 2). In the first movement, the basic materials are introduced $\left(\mathrm{L}_{1}-\mathrm{S}_{1}-\mathrm{L}_{2}-\mathrm{S}_{2}\right)$. The second movement is the dramatic culmination of the piece, where the composer-informant starts to mix the materials $\mathrm{L}$ and S, ending in full fragmentation of those. The last movement is an esoteric coda, where Melody is fabricated from the Space Music material. Next, I will explore and discuss the manifestations of compositional materiality and physicality in the process of creating the piece just described, starting from the role of visuality in the process. 


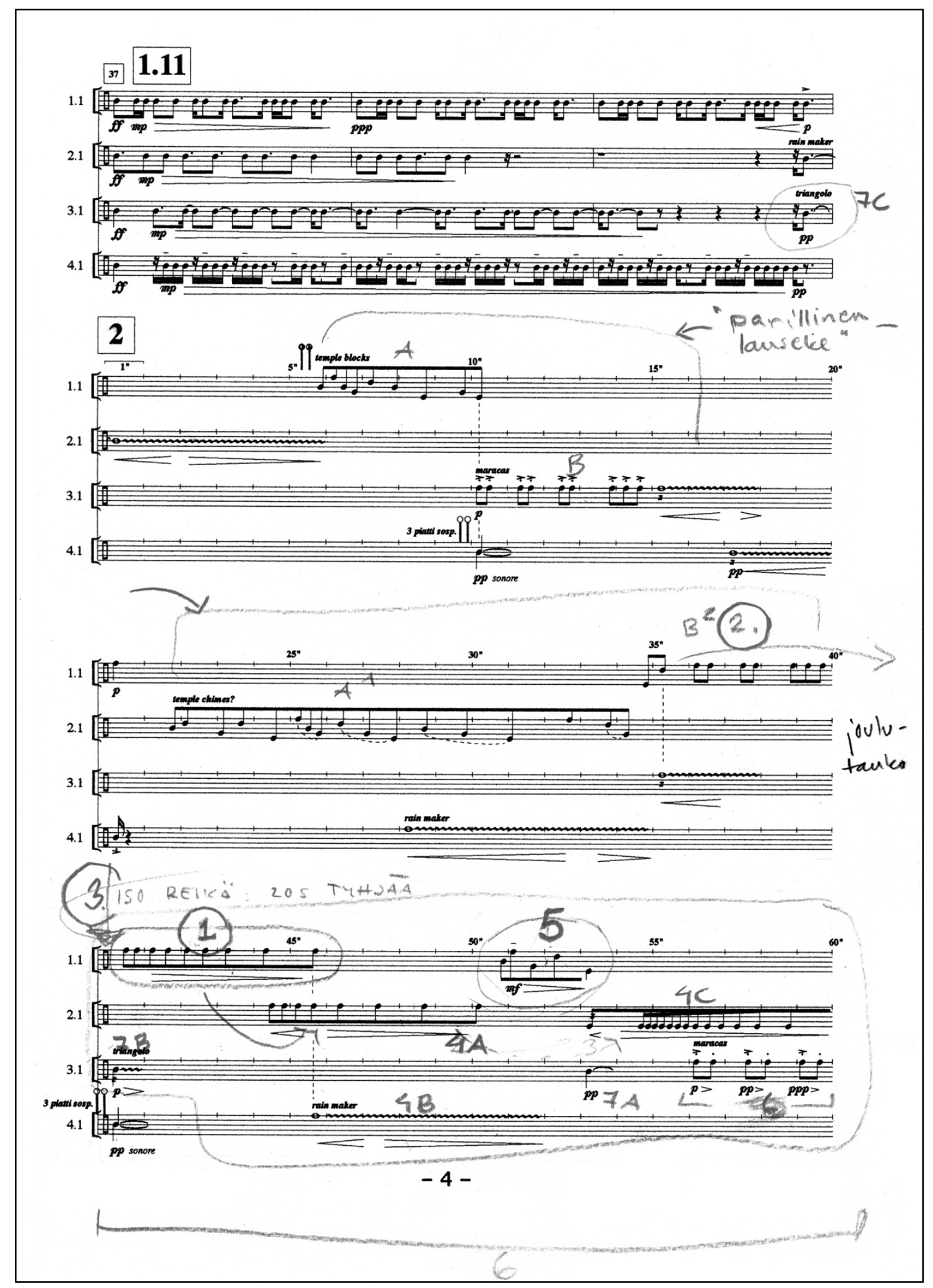

Figure 2. The first computer-typed manuscript, Dec 27th, 2004, discussed also dec 29th. Note. The first occurrence of Space Music ( $\mathrm{S}_{1}$; rehearsal no. 2) that begins after the coda $\mathrm{L}_{1}$ (rehearsal no. 1.11 in the manuscript; basic rhythms in contrapuntal setting). The composer-informant wrote numbers 1-7 to indicate the order of invention of the respective motifs. The capital letters $\mathrm{A}, \mathrm{B}, \mathrm{A}_{1}$, and $\mathrm{B}_{2}$ indicate a binary phrase construction ("parilinen lauseke;" the first handwritten text), within $\mathrm{S}_{1}$. "ISO REIKÄ 20 S TYHJÄ̈" means "big gap, 20 seconds blank." 


\section{Visualizing timbre and structure}

The most obvious material traits of a compositional process are notation and drawings on music paper. In the current study, visuality as such played a quintessential role in the beginning of the process. The germinal ideas of timbre, texture, or musical form were represented with visual metaphors as the composer-informant wrote into his diary before a single note was written into a music paper: "whiteness," "glacier," "sculpture," and "fresco." The visuality of these multi-sensory ideas reflects the synaesthetic nature of the germinal ideas, functions as a means of memorization of sensory ideas, and initiates the starting point of transformation of those ideas into musical notation.

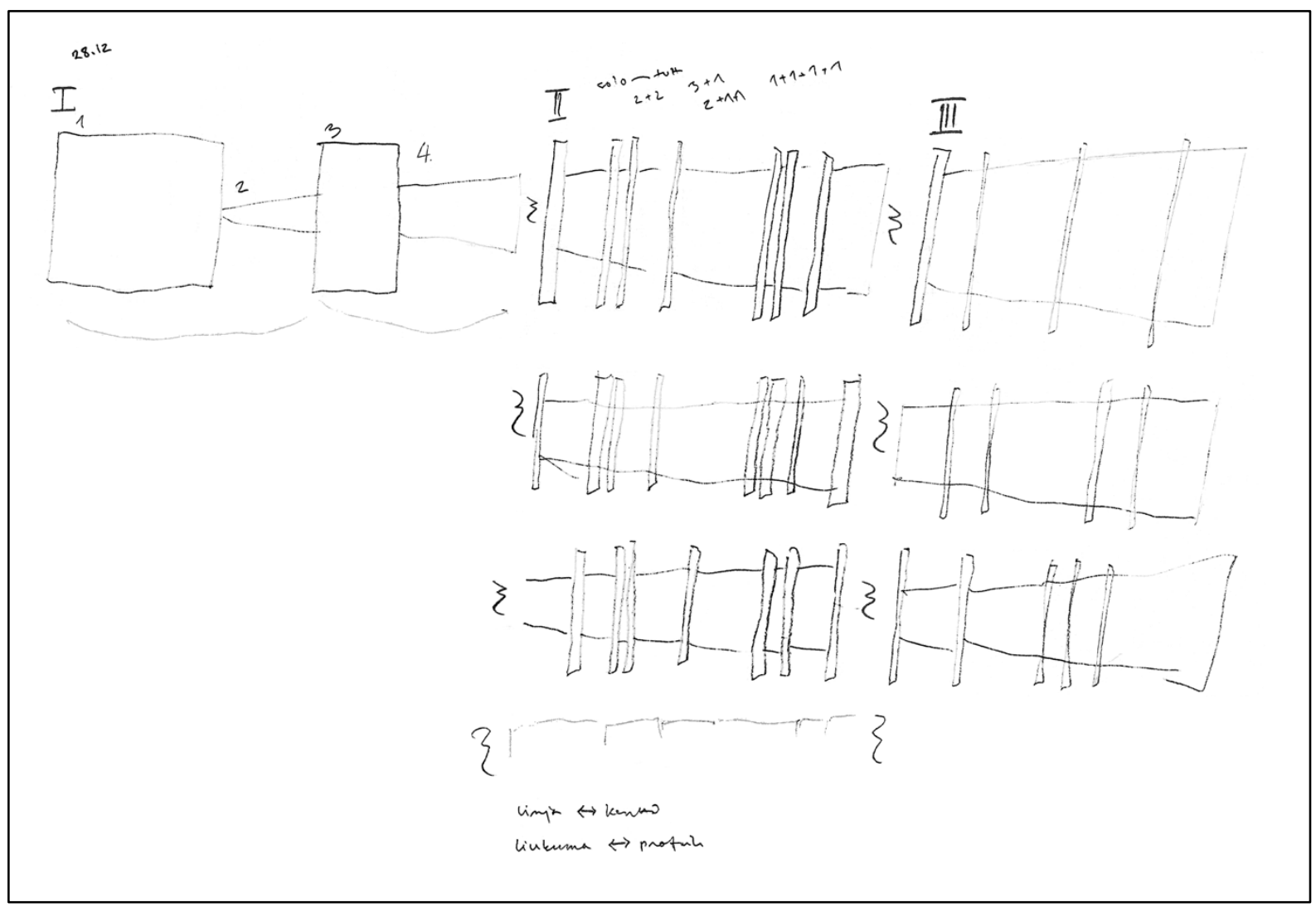

Figure 3. The sketch where the composer tested different options for the formal structure of second (II) and third (III) movements, Dec 28th, 2004.

Note. The curvy figures indicate rests (crotchets). The Arabic numbers in the first movement, with wedges indicating the idea of growth within the Linear Music of the first (I) movement, indicate rehearsal numbers in the score version. The numbers with +-marks above the second movement indicate the different musical settings (tutti-solo) of four percussionists, which the composer-informant made during the interview session.

Outlining the formal structure is the typical function of compositional drawings. Hence, visualization also proved to be the means by which the composer-informant made substantial decisions about the form of the piece. The first actual manuscript of the composing process of the current study was a drawing that depicts the structure of the whole piece (Figure 1), at the same time revealing almost all determinant ideas of the piece. Also, the sketch seems to indicate a one-movement form. However, during a later interview, after a lengthy incubation period, ${ }^{4}$ the composer-informant suddenly got an insight and reorganized the structure into three movements and wrote two times "beginning" ("Alku" in Finnish) to indicate the 
openings of second and third movements. A couple of weeks later he continued to ponder over the form through testing the different combinations of the Linear and Space Music at the beginnings of second and third movements: which music may end second movement and start third movement if second movement begins with Linear Music (two upper versions in Figure 3) or Space Music (two lower versions)? This compositional problem-solving venture fully reflects the way in which a composer (Roger Reynolds) used visual sketching to explore and assemble the temporal organization of two sections in his piece under construction, described in the study by McAdams (2004). Having explored the role and function of iconic material representations in composition I move on to discuss the role and function of notation.

\section{Preparing the score}

The quintessential function of notation, from the point of view of preparing a composition, is its capacity to materialize and externalize musical ideas for musicians to execute them. Moreover, externalizing mental ideas into fixed material form distributes the cognitive load of working memory and opens those ideas to be further explored, amended, and developed. Hence, notation may be viewed as a cognitive extension (Peréz-Echevarría, 2017). The compositional process of the composer-informant was permeated with the externalization of musical ideas into notes. Concurrent with the writing process, he analyzed and assessed the inscriptions as well as rethought the original idea behind those inscriptions, as shown in the next citation to come.

The composer-informant started the production of the score by handwriting — notifying that there is a difference in feeling between handwriting and typing - but turned quickly to his computer, typed the script, and printed out the first score version. First, because of the technical features of Finale software, described later, he defined the bars that he anticipated that he would need, according to the outline he had made earlier based on Figure 1. Then he started to fill in the gaps by hand, after which he typed the amendments. At this point, the composerinformant made some new amendments and corrections:

First, I wrote like this [shows the first score version] and then I noticed that there was too little space there and I wrote it again like this [shows the second score version] . . Finale helps within these kinds of issues because one can copy and paste everything and then change the time signature. . . When I start to type it in the computer, I kind of ponder about it once again. . . When one knows or at least thinks that one knows, one does not wish to write it all down by the pencil. One just writes some guidelines and then rephrases it when typing it into the computer. Obviously, when typed it may be altered again.

The functions and implications of handwriting and typesetting with the computer may be different, as observed by Schiavio et al. (2020; see also Zembylas \& Niederauer, 2018). One of the composers in their study reported the importance of "the act of marking the page" and "touch[ing] every page" (p. 11). This reflects the attitude toward the handwriting of the composer-informant of this study as giving "a down-to-earth feeling." In this study, the composer-informant mainly used the computer as a typesetter.

Each notation software may have a different impact on the creative work with its specific affordances and restrictions. Finale notation software used by the composer-informant is nowadays considered somewhat outdated. ${ }^{5}$ One of the most eminent disadvantages is its feature which insists that every inscription must be placed in a bar that has been established beforehand. In this particular case, where much of the composition was written without bar 
lines, the composer- informant had to "fool" the software in order to get what he wanted. There was, however, no sign of any compromises in notation made due to the software. In sum, the score was fabricated layer by layer, section by section (Pohjannoro, 2008, 2014, 2016). Rather than finishing the piece horizontally and linearly (i.e., measure by measure), it was as much made ready vertically, all over the piece at the same time. The last decisions in the score regarded instrumentation, performance and tempo indications. In one of the last points in the process, the composer-informant materialized the whole score and spread it on the floor to recall, evaluate, and proof-read the piece in its entirety. Moving on, I will look in the way the composer-informant arranged sounds and musical structures and embedded instrumental practices and the acts of the performers into notational inscriptions.

\section{The virtual performer, musical instrument, and imagined sounds}

The data of the current study substantiate the observation by Schiavio et al. (2020) about the intersubjectivity between the composer and the performer and the composer anticipating how their music would be executed through the movements of the performer. The different affordances of various instruments and their playing techniques evidently influenced compositional decisions, not only instrumentation-wise or regarding notational practices but in terms of aesthetic choices as well, as indicated by the composer-informant: "[T]his [pointing to a Linear Music passage in a manuscript] will be continuous without any pauses so that they [the musicians] are not able to change the mallets, unless I write a pause to someone."

The next quotation shows how the composer-informant, when writing two fermatas after another, may even have primed gestures that were irrelevant in the actual sound producing (see Figure 4). The composer is quite wordy when describing his intention, using linguistic terms and therefore obviously speaking about and pointing to musical gestures (metaphoric expressions italicized):

\footnotetext{
There are two fermatas one after another. One fermata [1st] indicates that they let the instrument [wood chimes and tam-tam; systems III and IV respectively, in Figure 4] resonate as long as the sound lasts. The [2nd] fermata on the bar line indicates that after the sound has faded they take one more fermata before the next [movement] begins. It is more like a punctuation pause [the 2 nd fermata] than a certain duration that is counted [like with the 1st fermata]. A written rest [instead of the 1 st fermata] seems to be more substantial, like a word compared with a comma. They might sound alike, though. But if the duration is written, one has to count it [1st fermata]. There is a limit, there, silence. It is the kind of silence where everybody is waiting. . for something. The tension must last. [. . ] It means that one [the musician] won't change page or do something else.
}

By the first fermata (before the bar line), the composer indicates that the musicians should not mute the sound decay after the attack of the tam-tam (or wood chimes). ${ }^{6}$ The second fermata (on the bar line) presents a dead moment indicating that the performers must act so that the tension continues till the next movement, which begins attacca (i.e., not move at all). ${ }^{7}$

A musician induces the instrument with all its affordances into a composing mind. Compositional knowledge about the whole ecology of a musical instrument entails not only its aesthetic connotations, different instrumental, stylistic, notational, and instructional practices but the whole understanding about the materiality of the instrument, the physical aspects of playing it, and different sounds and timbres produced by it as well (see Hogg, 2011). In the next quotation, the composer-informant ponders about the nature of the timbral progression between $S_{1}$ and $S_{2}$, a couple of days after the creation of $S_{1}$ in Figure 2 (metaphoric expressions italicized): 
There is a certain feeling of floating in this Space Music, at least so far, anyway. Maybe it shows to the listeners . . . I mean, at the end of the day the listener cannot know how the music has been written: with bars or with second notation, or whatever. But this is meant to present different experiences of rhythm and time, so that it would present two different worlds that encounter each other in different ways in different spaces.

The material aspects of sound and timbre are expressed by the composer-informant with metaphoric expressions, which indicate the sound character and his compositional aspirations when shaping this materiality according to his aesthetic ethos. In the following section, I explore the covert physical world of the composer-informant manifesting itself in the bodily capacity needed in intuitive work.

\section{Physical reactions and gut feelings}

Due to the nature of the qualitative data of this study designed to track compositional thinking, no concrete bodily action by the composer-informant was detected, apart from the score writing and some coincidental accounts: ${ }^{8}$ the composer-informant gained an insight of his germinal ideas for the composition at hand during a mundane engagement, manifested in the first metaphoric expressions described in the visualization section and sketched in Figure 2. The next quotation that was conducted during an interview before the composer-informant had actually started the piece, shows the intuitive emergence of a musical inspiration, during a physical act after a long episode of sitting by the desk. Later, this idea proved to be the determinant idea of the whole piece:

For example, the other night I was late at work and went downstairs to take a shower. Suddenly, an idea about a dense repetitive field of sounds with rhythms diverging out of it popped into my head for the percussion piece. It came with an image of a tone colour. It was an idea with a kind of sonic image attached to it.

Similarly, Zembylas and Niederauer (2018, pp. 87-90) reported seemingly composition-wise non-relevant physical activities of some composers, during which a composer got a significant idea or a solution to a certain problem.

Although the observations of the concrete bodily actions of the composer-informant are limited in this study, his body and physicality as such are not irrelevant in the act of composing: the intuitive mode of knowing ("gut feelings"; body knowledge in Zembylas \& Niederauer, 2018, pp. 97-101; Hodgkinson et al., 2008) entails bodily reactions (Hochman et al., 2009). Despite apparent immobility, the body of the composer-informant recurrently was far from inactive when making compositional decisions but vitally energetic and ample with inner motion, instead. Intuitive compositional acts outperformed reflection in the compositional thinking process. ${ }^{9}$ The paradigmatic example of an utterance indicating intuition is the frequent expression of the composer-informant: "I'll try this and let's see what becomes of it." Similarly, Zembylas and Niederauer (2018) describe composers "trying out" something (p. 86) and acting on the basis of body knowledge (pp. 97-101).

While Katz (2012; Katz \& Gardner, 2012) links intra-musical material to the intuitive processing mode and extra-musical material with the reflective mode, this study resulted in a more complex relatedness between different kinds of materiality and the information processing modes. It demonstrates a composer that may, contrary to the findings by Katz, treat purely musical material with rigorous reflection (e.g., the systematic and analytical creation of the Linear Music material and deciding the formal structure of the piece; see Figure 3) and extra-musical material intuitively (e.g., the intuitive exploration of different two 
time concepts in the floating Space Music quotation or intuitive transformation of visual images into musical notation through experimentation as described in the previous paragraph). Similarly, the study of Donin and Féron (2012) presents its participant Philippe Leroux demonstrating intuitive judgment when analyzing the score (i.e., utilizing the reflective mode). Leroux, an equally analytically oriented and "beyond-domain" composer with the composer-informant of this study, speaks intuitively about "feeling" or "seeing" with his mind's eye without being able to argue for his judgment (original italics):

I re-read [the unfinished score] it often, and what's more, for the third, a simulation in time is available, so I feel / I see very well the balance / if such and such a section might tend to unbalance the piece as a whole, I would feel it right away. It is at the beginning, perhaps, that that type of thing is the most critical. After, I could almost continue with my eyes shut. . . (p. 251)

A remarkable manifestation of intuition was attained when I happened to visit the studio of the composer-informant ninety months after the data production of this study. During a phenomenological interview that focuses on eliciting the informant's sensory and bodily experiences (Petitmengin, 2006; Petitmengin \& Bitbol, 2009) the composer-informant, squinting his eyes and looking diagonally upward - thus manifesting an intuitive state of mind (Petitmengin, 2006) - articulated his bodily sensations and emotional state of physical excitement and tension (dashes indicate pauses of different length):

One somehow feels that - - or one tries to tempt an insight - that what it's all about - what one is looking for - - One kind of enters into an alert state, one even feels it in the muscles - - One somehow sort of tries to concentrate on the thing and to shut off other things - - -

And --- One like waits for it, but one never knows when it comes, where it comes from, or what it's all about ---

It's like a bird in a bush - But when it comes, one knows: that's it. And one can't do it for long - - But one can work with stuff one has found for a long time. One cannot keep lurking in the long run, one wears out. At least I do. It's a bit like one should be ready to snatch someone. One feels it in the arms and in the legs and in one's back. ---

One kind of enters an alert state, one even feels it in the muscles -- One somehow sort of tries to concentrate on the thing and to shut off other things. And - One like waits for it, but one never knows when it comes, where it comes from, or what it's all about. - - -

The expressions resemble primitive stalking, as if the composer-informant was "hunting sounds,"--strikingly in accordance with intuition postulated as the evolutionary oldest form of reasoning (see Evans, 2010). The fact that the composer even gets physically tired clearly corroborates the corporeal consequences of the intuitive body state. Having scrutinized the way in which the composer-informant used physical energy in his creative endeavor, I will next discuss how he aspired to make his music actually do and move something, that is, how he wished his music to have some kind of effect on the listener.

\section{Moving sounds to move the listener}

In addition to visual and rhetoric metaphors the composer-informant used, instead of music analytical terms, metaphors expressing movement and transformation when describing his compositional actions and aspirations. The next quotation exemplifies the performative language of the composer-informant when accounting the construction of the transition from the first instance of Space Music to the second instance of Linear Music $\left(\mathrm{S}_{1}-\mathrm{L}_{2}\right)$. The numbers (1-7, Figure 2$)$ refer to the markings made by him during the interview session, to 
indicate the order of his amendments ${ }^{10}$ (the metaphoric expressions of movement and transition italicized):

It is a simple repetition that gets slower [1, Figure 2]. But the thing is if this would create some kind of change in here. So that this would continue what has just happened [2] and at the same time it would bring a new beginning here [3]. It is there just to articulate - there are coincidences of some kind that in a way create an image or situation of arriving and leaving a place. Some figure ends and another thing begins and a single tone [7B] has been added to this point of an encounter that differentiates from those other two ... [It did not feel good I]n away that when this [5] is missing this [1,4A] ends too early in respect to this $[4 \mathrm{C}]$. They are events so similar to each other that another short event is needed between them. Because otherwise it just ends. And then there is another ending. But there is no inducement whatsoever to motivate that end.

Music analytically, the composer-informant was constructing a coda into the ending of $\mathrm{S}_{1}$ that concurrently introduces the next section, $\mathrm{L}_{2}$ (not shown in Figure 2). This "introductory coda" transforms the atmosphere of Space Music to the beginning of Linear Music by repeating and transforming the S-motives (tremolos, repetitive and melodic elements), designing continuities $(2-1,4 a, 4 c)$ and discontinuities $(5,7 a-c)$. Actually, the composerinformant, while explaining his compositional decisions retrospectively, got an insight that $\mathrm{S}_{1}$ may be analyzed as a binary construction $\mathrm{A}-\mathrm{B}-\mathrm{A}_{1}-\mathrm{B}_{1}$ (as marked by the composer-informant in Figure 2).

The artistic "content" of the section just analyzed seems not to be, in the mind of the composer-informant, first and foremost musicological but performative. His artistic aspiration is to perform some kind of transformation: an impression of an ambiguous situation where something is concurrently ending and beginning. This something is getting transferred or moved while leaving a place and going somewhere else, ending a passage and beginning a new one. Rather than being translated into music analytical or expressive-figurative language, both used elsewhere in the data, the verbal account is full of conceptual metaphors ("understanding and experiencing one kind of thing in terms of another"; Lakoff \& Johnson, 1980, p. 5) that try to express the musical gestures that somehow render the artistic content or substance, metaphorically speaking: moving or acting of an abstract agent in a musical scene.

The "pushing of forms and sounds" into motion (cp. "tonally moving forms" by Hanslick, $1854 / 1986$, p. 29), indeed is the laborious work by the composer, not only that of the performer. The sounds, being material entities with inertia, have to be "set", even "forced" to "move". This labor of constructing the "sounding world" (Reybrouck, 2006) is predominantly made by the intuitive processing mode that entails bodily reactions analogous to those of the listeners (i.e., shivers, a lump in the throat, heart palpitation, sweating). The sounds need to be "moved" into their proper "places" and this makes the construction, the "dead" and "motionless" score, loaded with agency and signification and therefore, promoting the potential motion of the listener.

\section{Conclusion}

The key findings of this study may be organized into five aspects of physicality and materiality in the compositional thinking process: (1) visual imagination and visual representation as inspiration and as a cognitive asset facilitating the creative process, (2) notation and the score as the material object and cognitive extension of composition, (3) the materiality and physicality of sounds and timbres as well as sources and the agents producing those sounds and timbres, (4) physical reactions entailing embodied intuitive knowledge of 
the composer, and (5) metaphorical processes, where metaphoric expressions manifest the way in which the composer, when shaping timbres and musical structures, "pushes" sounds to sound and "move" in a way that is significant to him. This performative power is transmitted to the listener as the meaningful expressivity of music, which makes music move the emotions of the listener.

The results demonstrate a composer who was reliant on and inspired by the materiality of sound and musical instruments, but on the other hand constrained and challenged by the corporal and physical affordances of performers and their instruments as well as by the (im)practicalities and intelligibility of the notational system.

Although this case study may not be fully generalisable to all compositional processes in their entirety, it has been able to demonstrate some key elements and functions of compositional materiality and physicality characteristic of the creative mind also more widely (see Gomm et al., 2009). The findings may provide fruitful information for research on the similarities and the differences of materialities and physicalities between composers and performers.

Notes

1. While the data of this study capture, by definition, a situational, singular, and unpredictable creative process (i.e., a compositional process may vary not only among different individuals but also develop within a single person over various tasks or time), they at the same time reflect the shared biological and physiological foundations that condition the human (embodied) cognition. Therefore, the fact that the data were produced over 15 years ago does not dilute their evidential value in demonstrating the material and physical aspects of composing, in the context of a Western classical music composer inventing and writing down a full score to be executed by musicians with their instruments.

2. I am using the term composer-informant, when referring to the composer of this study; otherwise, composer is used in neutral gender (they).

3. See Moisala (2011), about composers' contradiction of interests between their reflective openness and public images.

4. Incubation means a period of idle time regarding compositional thinking, not consciously contemplating any compositional problem (Sio \& Ormerod, 2009).

5. The composer-informant has already purchased a new software but has had neither time to get acquainted with it nor desire to update the operating system of his computer to fit this software. This is because he thinks this would probably mess his not so new operational environment with several outdated programs he uses.

6. Notice that it is possible to change the sound decay after the sound producing action within some musical instruments, such as wood chimes, tam-tams and many metallic percussion instruments, but not within some other instruments, for example, within pianos or string instruments played by a bow.

7. These two fermatas are tricky to interpret and might exemplify a break in the communication between composers and performers (Pohjannoro, 2020). However, when recently consulting a professional percussionist accustomed to contemporary repertoire, they realized the difference. The composer-informant, when being informed about the solution of the percussionist, was happy with their interpretation of muting the decay at the second fermata.

8. The obvious bodily actions by a composer would include probing with a musical instrument and writing the score by hand or with the computer.

9. See Pohjannoro (2014) about the difficulties in defining intuition theoretically and operationally.

10. During the same interview session, section S1 was discussed twice: first with a former score version of it and then with a new print (Figure 2) where the composer made his markings in order to account the order of his actions. This lengthy interview episode, out of which but a tiny fraction is presented here, with its abundant metaphoric expressions, exemplify, in epistemic terms, one of the most intense and detailed manifestations of compositional thinking-in-action (Schön, 1983), that is, thinking while composing, in the data. 


\section{References}

Collins, D. (2005). A synthesis process model of creative thinking in music composition. Psychology of Music, $33,193-216$.

Donin, N., \& Féron, F.-X. (2012). Tracking the composer's cognition in the course of a creative process: Stefano Gervasoni and the beginning of Gramigna. Musicae Scientiae, 16, 262-285. https://doi. org/10.1177/1029864912448328

Ericsson, K. A. (2003). Valid and non-reactive verbalization of thoughts during performance of tasks. Journal of Consciousness Studies, 10(9-10), 1-18.

Ericsson, K. A., \& Simon, H. A. (1993). Protocol analysis: Verbal reports as data. MIT Press. (Original work published 1984)

Evans, J. S. B. (2010). Intuition and reasoning: A dual-process perspective. Psychological Inquiry, 21(4), 313326. https://doi.org/10.1080/1047840X.2010.521057

Gass, S. M., \& Mackey, A. (2000). Stimulated recall methodology in second language research. Lawrence Erlbaum.

Gomm, R., Hammersley, M., \& Foster, P. (2009). Case study and generalization. In R. Gomm, M. Hammersley, \& P. Foster (Eds.), Case study method (pp. 98-112). SAGE.

Hanslick, E. (1986). On the musically beautiful: A contribution towards the revision of the aesthetics of music (G. Payzant, Ed. \& Trans.). Hackett. (Original work published 1854)

Hochman, G., Glöckner, A., \& Yechiam, E. (2009). Physiological measures in identifying decision strat- egies. In A. Glöckner \& C. Wittman (Eds.), Foundations for tracing intuition: Challenges and methods (pp. 147-167). Psychology Press.

Hodgkinson, G., Langan-Fox, J., \& Sadler-Smith, E. (2008). Intuition: A fundamental bridging con- struct in the behavioural sciences. British Journal of Psychology, 99(1), 1-27. https://doi. org/10.1348/000712607X216666

Hoffman, R. R., Shadbolt, N. R., Burton, A. M., \& Klein, G. (1995). Eliciting knowledge from experts: A methodological analysis. Organizational Behavior and Human Decision Processes, 62(2), 129-158. https://doi.org/10.1006/obhd.1995.1039

Hogg, B. (2011). Enactive consciousness, intertextuality, and musical free improvisation: Deconstructing mythologies and finding connections. In D. Clarke \& E. Clarke (Eds.), Music and consciousness: Philosophical, psychological, and cultural perspectives (pp. 79-93). Oxford University Press.

Hovland, E. (2017). Fantasizing at the guitar: Remarks on the compositional practice of Hector Berlioz. Music \& Practice, 3. www.musicandpractice.org/volume-3/guitar-compositional-practice-berlioz/

Hovland, E. (2019). Who's Afraid of Berlioz? Studia Musicologica Norvegica, 45(1), 9-30.

Jack, A. I., \& Roepstorff, A. (2002). Introspection and cognitive brain mapping: From stimulus-response to script-report. Trends in Cognitive Sciences, 6(8), 333-339. https://doi.org/10.1016/S13646613(02)01941-1

Katz, S. L. (2012). The influence of the extra-musical on the composing process. In D. Collins (Ed.), The act of musical composition: Studies in the creative process (pp. 171-186). Ashgate.

Katz, S. L., \& Gardner, H. (2012). Musical materials or metaphorical models? A psychological investigation on what inspires composers. In D. Hargreaves, D. Miell, \& R. MacDonald (Eds.), Musical imaginations: Multidisciplinary perspectives on creativity, performance, and perception (pp. 107-123). Oxford University Press.

Lakoff, G., \& Johnson, M. (1980). Metaphors we live by. The University of Chicago Press.

Lincoln, Y., \& Guba, E. (1985). Naturalistic inquiry. SAGE.

McAdams, S. (2004). Problem-solving strategies in music composition: A case study. Music Perception, 21, 391-429. https://doi.org/10.1525/mp.2004.21.3.391

Moisala, P. (2011). Reflections on an ethnomusicological study of a contemporary western art music composer. Ethnomusicology Forum, 20(3), 443-451. https://doi.org/10.1080/17411912.2011.659025

Peréz-Echevarría, M.-P. (2017). The music scores as external representational systems: Teaching and learning. Finnish Journal of Music Education, 20(1), 114-116.

Petitmengin, C. (2006). Describing one's subjective experience in the second person: An interview method for the science of consciousness. Phenomenology and the Cognitive Sciences, 5, 229-269. https://doi.org/10.1007/s11097-006-9022-2

Petitmengin, C., \& Bitbol, M. (2009). The validity of first-person descriptions as authenticity and coherence. Journal of Consciousness Studies, 16(10-12), 363-404.

Pohjannoro, U. (2008). Views along a pathway. Empirical observations over composing process. Musiikki/ Journal of the Finnish Musicological Society, 38(3-4), 218-274. (In Finnish)

Pohjannoro, U. (2012). Tracking composer's thinking in action with the stimulated recall method. Possibilities, challenges, and limitations. Finnish Journal of Music Education, 15(1), 24-38. (In Finnish) 
Pohjannoro, U. (2014). Inspiration and decision-making: A case study of a composer's intuitive and reflective thought. Musicae Scientiae, 18(2), 166-188. https://doi.org/10.1177/1029864914520848

Pohjannoro, U. (2016). Capitalising on intuition and reflection: Making sense of a composer's creative process. Musicae Scientiae, 20(2), 207-234. https://doi.org/10.1177/1029864915625727

Pohjannoro, U. (2020). Embodiment in composition: 4E theoretical considerations and empirical evidence from a case study. Musicae Scientiae. Advance online publication. https://doi.org/10.1177/1029864920961447

Pohjannoro, U., \& Rousi, A. (2018). The modes of music information in a compositional process: A case study. Journal of Documentation, 74, 987-1007. https://doi.org/10.1108/JD-10-2017-0141

Reybrouck, M. (2006). Musical creativity between symbolic modelling and perceptual constraints: The role of adaptive behaviour and epistemic autonomy. In I. Deliège \& G. Wiggins (Eds.), Musical creativity: Multidisciplinary research in theory and practice (pp. 42-59). Psychology Press/Taylor \& Francis.

Reynolds, R. (2004). Compositional strategies in The Angel of Death for piano, chamber orchestra, and computer-processed sound. Music Perception, 22(2), 173-205. https://doi.org/10.1525/mp.2004.22.2.173

Roels, H. (2016). Comparing the main compositional activities in a study of eight composers. Musicae Scientiae, 20(3), 413-435. https://doi.org/10.1177/1029864915624737

Ryan, K., \& Schiavio, A. (2019). Extended musicking, extended mind, extended agency. Notes on the third wave. New Ideas in Psychology, 55, 8-17. https://doi.org/10.1016/j.newideapsych.2019.03.001

Schiavio, A., Moran, N., van der Schyff, D., Biasutti, M., \& Parncutt, R. (2020). Processes and experiences of creative cognition in seven western classical composers. Musicae Scientiae. Advance online publication. https://doi.org/10.1177/1029864920943931

Schön, D. (1983). The reflective practitioner: How professionals think in action. Basic Books.

Sio, U. N., \& Ormerod, T. C. (2009). Does incubation enhance problem solving? A meta-analytic review. Psychological Bulletin, 135(1), 94-120. https://doi.org/10.1037/a0014212

Stake, R. (2005). Qualitative case studies. In N. Denzin \& Y. Lincoln (Eds.), The Sage handbook of qualitative research (3rd ed., pp. 443-466). SAGE.

Zembylas, T., \& Niederauer, M. (2018). Composing processes and artistic agency: Tacit knowledge in composing (T. Genrich, Trans.). Routledge. 